\title{
An Analysis of 'Emotions' in Transgender through Facial Action Coding System
}

\author{
Sugyanta Priyadarshini \\ KIIT Deemed to be University, Bhubaneswar, Odisha, India \\ riro231110@gmail.com, ORCID: oooo-ooo1-766o-6162
}

\begin{abstract}
Transgender is a blanket term wrapping individuals whose gender identity, expression or behavior transgresses their biological sex. They are often put on the periphery in terms of finances and the social inclusion. The varying stereotypes of sexual binary recognize the transgenders as socially misfit and economically unaccepted. Emotionally, the transgenders face hardships and lack of social support that push them at the social cross-roads in terms of denial and rejection. Nevertheless, this emotional distress is generally aggravated by the family, friends and acquaintances. This paper examines the emotional binary of Transgenders and parents after their detachment by using an automatically based system on facial gestures called Facial Action Coding system (FACS). Further, their affirmative emotions, such as, Happiness, Sadness, Anger, Disgust, Contempt, Surprise, and Fear is rated with an intensity rate justifying the strength of the respective emotion. The FACS analysis of emotion of sadness resulting in depression is evaluated by using 20-item measure of the Center for Epidemiologic Studies-Depression Scale (CES-D). The paper also explores the facilitative coping experiences after the recognition of the sexual identity by noting down the broad scale of emotional bandwidth. However, facial expressions of transgender respondents and their parents are recorded and are selected based on snow ball sampling. The research work has analyzed emotions of transgender respondents and their parents to know the ground reality of real troubles they come across standing on periphery of the society.
\end{abstract}

Keywords: Transgender, Parents, FACS, Emotions, Facial expressions, CES-D.

\section{Introduction}

Gender exists on a continuum of binaries between men and women. These binaries are in general a part of larger spectrum of the society that constitutes the mankind as a whole. Under this spectrum, there exist the community of transgender people who come in between the most accepted binary division of sexes i.e. male and female. Transgender is an umbrella term that includes individuals whose gender identity, expression or behavior mismatches from their sex. They are the most unaccepted gender - variant who often tussle with the stigma and discrimination that makes them socially misfit. Transgenders often experience instinctive dislike for their unacceptable uniqueness. This dislike is expressed in the form of denial and rejection mostly reciprocated from their family, friends and relatives. The distinction of sex biasedness and isolation from the social system often generate an impression of worthlessness and being left out from a larger social circle. The shrink in their expansive identity forces them to live their life in

(C) AesthetixMS 2020. This Open Access article is published under a Creative Commons Attribution Non-Commercial 4.o International License (http://creativecommons.org/licenses/by-nc/4.o/), which permits non-commercial re-use, distribution, and reproduction in any medium, provided the original work is properly cited. For citation use the DOI. For commercial re-use, please contact editor@rupkatha.com. 
the periphery or on societal margins. This targeted experience owes them a dismal dejection of dreams of living a blissful life. The rebuff or maltreatment by the parents of transgenders interrogates their existence due to constant rejection by their intimate social circle. The emotions such as, isolation, hatred, pessimism, worthlessness and stress triggers mélange of various experiences of extremism in their personal life. The maltreatment during their childhood make them aggressive or anxious which has an adverse impact on their emotional competence. Boycott from parents and detachment from home often put transgenders in the emotional quagmire that impacts their life significantly. The Parental Acceptance-Rejection (PAR) theory indicates that a child's experience of rejection may have a significant impact on their adult lives. Due to the societal mind set of unacceptance of Transgender, fear of losing near and dear relatives or dropping dignity in the society; the family goes through shock, denial and anger while discovering their child as a transgender. However, at the same time, it is important for parents to bargain their emotions and accept their children the why they are born.

\section{Review of Literature}

Transgender individuals stand at the crossroads of the binary of sexes. Their unique appearance, display of feminine behavior apart from being a man and variation from stereotypes has become the major reasons behind their unacceptability and denunciation. Due to the collective rejection on these grounds; they are abandoned by their parents, bigoted by their relatives and deserted by their peers (Grossman \& D'Augelli, 2006; Lombardi, 2001; Mallon, 1999; Ryan \& Futterman, 1998). Thus, they become victims to several prejudices and are subjected to physical and verbal abuses (Klein, 1999). The orthodox mindset of society considers transgender people as potential enough for entertaining others thereby, repudiating them from availing any respectable jobs. As a result, it becomes difficult for them to find a suitable job and maintain a dignified life. Ultimately, finding no way out they get dragged into begging, sex works and other inappropriate jobs (Singh, 2018). To begin with family, most of the transgenders are thrown out from family due to the fear of losing dignity in the society whereas some prefer to run away as they do not want to bring shame or disgrace to their family (Pattnaik \& Mohanty, 2014). A study conducted on 295 transgender adults including transwomen and transmen and their non-transgender siblings found that transgender adults received less of support from their families and more of harassment, violence and discrimination in the hands of peers in comparison to non-transgender siblings (Factor \& Rothblum,2007). Further, fifty-five transgender adolescents were interviewed to which more than half of the sample reported that their parents are aware about their transgender identity but have a negative reaction towards their coming out (Grossman \& D'Augelli, 2006). Even, few transgender individuals voiced that their parents tried to kill them or physically torture them till they try committing suicide. However, it was estimated that around $64 \%$ of transgender respondents face rebuff from their family in Odisha and this is the major reason behind renouncing their family (Pattnaik \& Mohanty, 2014). According to a survey conducted in 2011, approximately $41.2 \%$ of Hijra were rejected by their own family due to their unaccepted gender status. A number of authors have focused on the issues that parents have to face when they realize the true gender reality of their Transgender child (Elis \& Eriksen, 2002; Vanderburgh, 2007; Wren, 2002). Lev (2004), devised the idea of "family emergence" to explore the problems of self-recognition through challenges and negotiation in "finding balance". Familial rejection has sufficient impact on transgender which brings negativity to their mind and drop down their mental health and economic security resulting in health hazards. Health hazards such as depression, homelessness, loneliness, and suicidal ideas can put an end to life of Transgender 
people. But, studies have discovered that support from parents and social circle can act as a protective shield against psychological distress of transgenders (Vanderburgh, 2007).

\section{Purpose of the Study}

The purpose of this pragmatic approach is to examine the feelings of MTF ${ }^{1}$ transgender people and their parents after banishing them from their shelter. The following questions were addressed:

- Is there any negative impact on transgender parents after discarding their transgender child?

- Do transgender parents feel guilty over discarding their transgender child due to societal pressure?

- What are the possible positive and negative feelings of Transgender after renouncing home?

\section{Methodology}

The study is an amalgamation of two arms of research comprising of qualitative and quantitative approach of data analysis and data collection. Data is collected from seventy-five transgender aging 10-41 years who were identified through snow ball sampling. Data regarding transgender is fetched by visiting three prominent areas of Bhubaneswar (Odisha, India) and its periphery, i. e., Pallashpalli, Vani vihar and Behera Sahi of Satya Nagar. Further, data is collected from 5 transgender parents by visiting to their house in the villages of Panchapalli, Retang and Sana Nua gaon. Data is collected during the leisure time of these respondents. However, it took 7 months to collect data from respondents. To access the ground reality and emotional turbulence among transgenders; the data has been collected from unorganized sector. The views of transgender and their parents were recorded and were translated from Odia to English. Facial expression was noted down and was used to verify and determine emotions through facial expression by using FACS. Further, interviews were done repeatedly and at the regular basis. To this end, questionnaire was prepared and views of transchildren were noted down. The FACS analysis of emotion of sadness resulting in depression is evaluated by using 20-item measure of the Center for Epidemiologic Studies-Depression Scale.

\section{Discussion}

Facial actions coding system was developed by Paul Ekman and Wallace Friesen in 1978 but later it was rebooked by WV Friesen and JC Hager in 2002. However, it was initially originated by CarlHerman Hjortsjö in 1970 with 23 facial movements. Facial action coding system is an automatically based system that supports comprehensive description of an anatomical movement of the facial gestures. As described by FACS codes, every facial movement can be decoded on the basis of action units. Hence, FACS operates and analyzes the human emotional behavior objectively. However, these action units help to decode expressions of the transgenders under 7 categories of Happiness, Sadness, Anger, Disgust, Contempt, Surprise and Fear (Ekman et al. 2002). For expressions to be considered positive or negative, the action units need to receive a minimum intensity puller of 'b' or 'c' individually owing to Friesen's and Ekman's (1992) visual guide book.

\footnotetext{
${ }^{1}$ MTF- Male to Female transgender
} 


\begin{tabular}{|c|c|c|}
\hline Sl.no & Emotions & Facial descriptions \\
\hline 1 & Happy & Cheek Raiser, Lip Corner Puller \\
\hline 2 & Sadness & $\begin{array}{c}\text { Inner Brow Raiser, Brow Lowered, Lip Corner } \\
\text { Depressor }\end{array}$ \\
\hline 3 & Surprise & $\begin{array}{c}\text { Inner Brow Raiser, Outer Brow Raiser, Upper Lid } \\
\text { Raiser, Jaw Drop }\end{array}$ \\
\hline 4 & Fear & $\begin{array}{c}\text { Inner Brow Raiser, Outer Brow Raiser, Brow } \\
\text { Lowered, Upper Lid Raiser, Lid Tightened, Lip Stretcher, } \\
\text { Jaw Drop }\end{array}$ \\
\hline 5 & Anger & $\begin{array}{l}\text { Brow Lowered, Upper Lid Raiser, Lid Tightened, } \\
\text { Lip Tightened }\end{array}$ \\
\hline 6 & Disgust & $\begin{array}{l}\text { Nose Wrinkler, Lip Corner Depressor, Lower Lip } \\
\text { Depressor }\end{array}$ \\
\hline 7 & Contempt & Lip Corner Puller, Dimpler \\
\hline
\end{tabular}

Table. 1. List of emotions and facial expressions, Source: A visual Guidebook FACS

\section{Measuring "Happiness" in Transgender respondents and their Parents}

'Happiness' is an emotion based on the significant pillars of positive psychology that revolves around the cognitive wellbeing of society. Despite being equally created by the creator, Transgender is thrust back into conflict between conservative and liberal values of Indian society, hampering their wellbeing and happiness.

In order to find out how far transgender people are happy in their life, 75 transgender respondents were asked questions regarding their experiences about their transition phase, parental relationships, current life, and romance in their life. However, when asked, "Are they happy being a transgender person"; eight transgender respondents exhibited their happiness by raising their cheeks and pulling their lip corners to an intensity pull of ' $b$ ', but twelve agreed to it additionally by lowering their brows which can also be related to their anger or sadness initiated from their personal experiences after coming out as a transgender person. On the basis of FACS, $10.6 \%$ of sample were happy being born as a transgender. Further, when asked "whether they blame their identity for their rough struggle," $20 \%$ happily agreed that they do not blame their identity for their rough struggle. Questioning them about " How far are they satisfied staying far away from home," 30.66\% transgender respondents said yes, which was in sync with their facial expression of happily staying away from home. Lastly, asking them, "Are you happy staying with transgender friends" $86.66 \%$ transgender happily said yes by raising their cheeks higher and pulling their lip corner wider. Fig.1a shows the proportion of transgender people who are happy being born as a transgender person (10.6\%), from leading a life as a transgender person (20\%), from staying away from home (30\%) and staying with their transgender friends $(86.66 \%)$.

In order to map the happiness of the parents of transgenders; two questions were asked individually such as "Are you happy being a parent to a transgender child?" and "Are you happy keeping your transgender child away from you?". However, all the twenty respondents were not happy being a parent to a transgender child. Further seventeen out of twenty expressed their happiness to an intensity of rating 'a' from keeping their transgender child away from them. None of them were happy being parent to a transgender child and eight are relieved by keeping their transgender child away from them. The given above Fig 1 b shows that twenty respondents were 
not happy being a parent to a transgender child and $40 \%$ of the sample expressed their happiness staying away from their transgender child.


Fig 1: Measurement of Happiness in transgender respondents and their parents

\section{Measuring "Sadness" in Transgender respondents and their Parents}

According to Roeckelein, 2006,sadness is a feeling that creates unpleasantness. This then prompts people to move away from the source of this irritation, which can be one of the reasons behind transgender people renouncing their parents and peers. The emotion of sadness is deeply entrenched in an individual's life. It occurs when one loses a valued person, fails to achieve a goal, or loses their sense of control. In the case of transgender people, most of them remained sad due to the lack of connectivity with parents and humiliation from society.However, when asked "whether they were upset being born as a transgender person,"; sixty-seven transgender respondents depicted the emotion of sadness by raising inner brows, lowering brows, and depressing lip corner with intensity of rate 'c,'. Further, when asked "whether they blame their transgender identity for their rough struggle," sixty respondents said yes with the anatomical movement of expressing sadness, which means they blame their unique identity for their struggles in life. Questioning them about "Satisfied staying far away from home," Fifty-two transgender respondents said no, which was in sync with their facial expression of sadly staying away from home. Lastly, asking them, "Are you happy staying with transgender friends" ten transgender sadly said yes with raising inner brows, lowering brows, and depressing lip corner. Fig.2a. Shows the proportion of sad transgender people who are unhappy being born as a transgender person (67), blame their identity for their rough journey (6o), dissatisfied staying away from home (52) and disappointed staying with their transgender friends (10).

Transgender parents were found sad and disappointed for either being destined to have a transgender child or because of their inability to convince others regarding the acceptance of their transgender child. None of the fathers from the sample was sad about discarding their transgender child. Instead, they proudly admitted their harsh behavior with their child. Some of the mothers of transgender people were in grief after their child was thrown away from home. Figure $2 \mathrm{~b}$ shows that three out ten mothers expressed their sadness of failing as a mother to their transgender child. Whereas, in the case of fathers, $100 \%$ of the sample were upset to be the father of a transgender child. None of them were happy being recognized as a father to a transgender. 


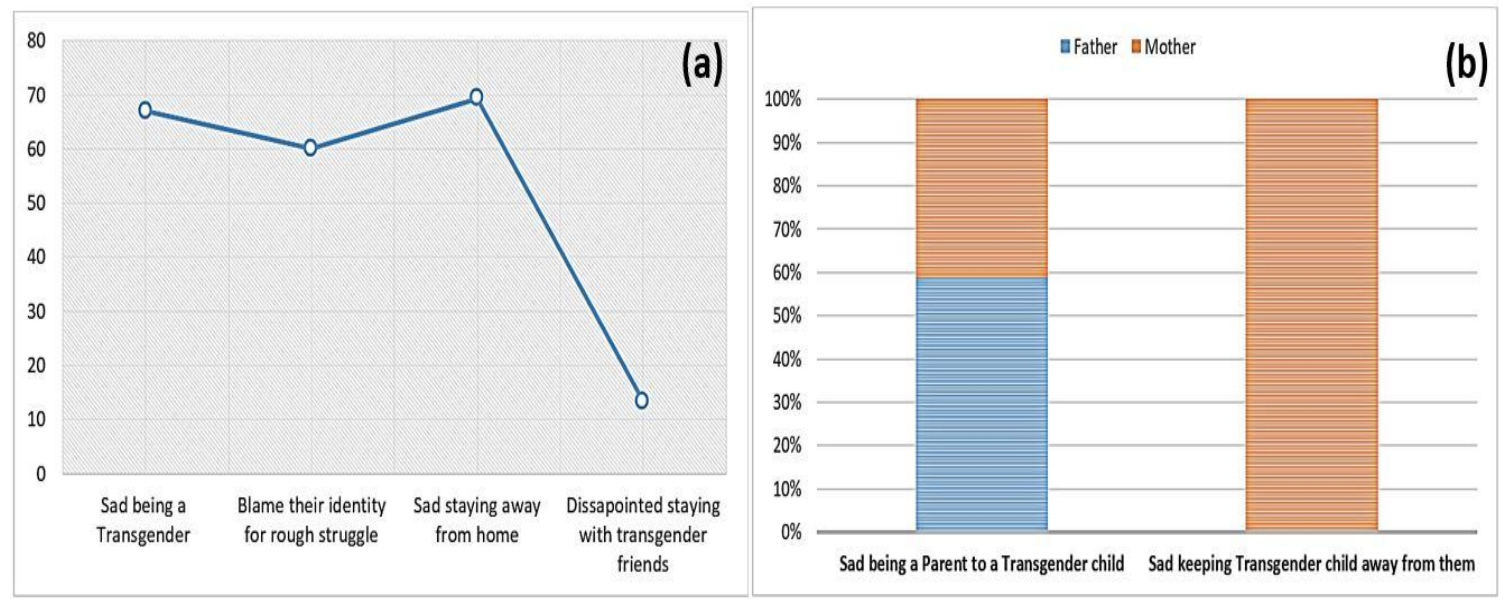

Fig 2: Measurement of Sadness in transgender respondents and their parents

\section{Measurement of Depression in Transgender through Center for Epidemiologic}

\section{Studies-Depression Scale}

The impact of harsh parenting and rough struggle pushes most of the transgender respondents towards depression which was identified by providing them a questionnaire (e.g., I do not have anything to look forward) to evaluate certain persistent symptoms such as loneliness, insomnia and suicidal ideas. Participants were advised to rate the statements on a 4-point Likert scale $(\mathrm{o}=$ Rarely, $1=$ Little times, $2=$ Occasionally, $3=$ Most of the times). However, CES-D is utilized to find out the level of depression transgender respondents have come across (Radloff, 1977). A dichotomous variable was put forth with a cut off of $16(0=$ tally $<16$ and $1=$ tally $>16)$. It was found that $65 \%$ of transgender respondents were going through depression and need medical attention.

\section{Measuring the emotion 'Surprise' in Transgender respondents and their Parents through FACS}

The surprise is a psychological state bringing a sense of astonishment or amazement from any unexpected event. This emotion arises due to the mismatch between expectation and actuality. In the case of transgender people, they are usually surprised when they identify their true identity. Similarly, the parents of transgender people are astonished to discover their child as a transgender person. When asked about their reaction about discovering their true gender identity, seventy-five transgender respondents agreed that they were surprised to recognize the truth. However, out of seventy-five transgender people, eight transgender people considered it as a pleasant surprise, whereas rest sixty-seven were disappointed with this unpleasant surprise. Eight transgender people were happy because they finally understood the reason behind the difficulties they were facing in accepting their bodies. Remaining, sixty-seven were disappointed because they could visualize the consequences of being a transgender person. These respondents raised their inner brows and outer brows and dropped their jaws during and after narrating their past. The news of being a transgender parent was an unpleasant surprise for the complete sample. None of the parents consider the "news" as a pleasant surprise; instead, most of the parents reacted to this truth furiously. On the other hand, the complete interviewed sample of 
transgender parents considered "coming out" of their child as Transgender was an unpleasant surprise for them. Fig. 3 shows the "coming out ${ }^{2 "}$ of transgender people as a pleasant surprise or an unpleasant surprise for both transgender people and their parents.

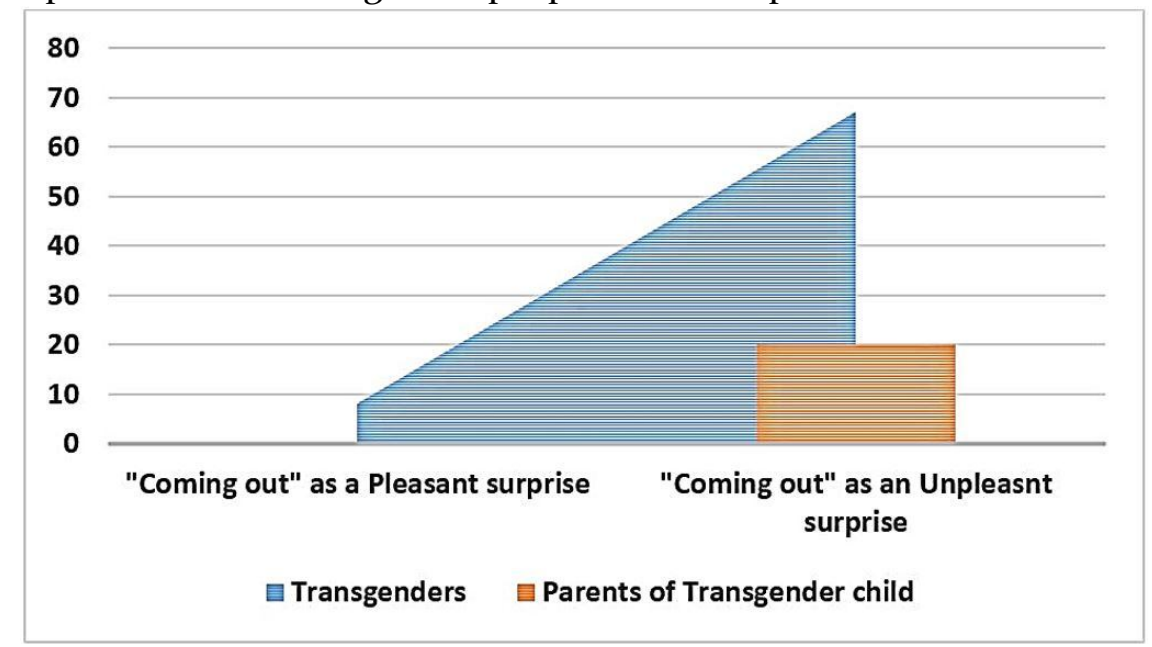

Fig 3: "Coming out" as a pleasant or unpleasant surprise for transgender and their parents

\section{Measuring the emotion 'Fear' in Transgender respondents and their Parents through FACS}

Fear is a powerful and primitive human emotion-induced from the presence of threat or danger, leading to the fight-or-flight response. Taking transgender people into account, most of them do not want to confront their gender identity to the world as they fear losing their family and peers after coming out. Most of the parents do not understand and accept their child's unique identity, and for the sake of their dignity in society, they boycott their transgender child. When questioned about whether they feared to lose their family before coming out, $92 \%$ of transgender respondents were scared of losing their parents and relatives because they did not know where to go if they are deserted by their family members. Questioning them on whether they were scared coming out as transgender; $89.33 \%$ of transgender people feared coming out as they were aware of the consequences they would face after being identified as a transgender person. However, when asked about whether they fear to face their parents again after being thrown away from family, $82.6 \%$ transgender people agreed to it. Lastly, around $86.66 \%$ of the sample was afraid of living an isolated life in the absence of their social circle. Fig 4. shows the proportion of transgender people fearing from losing family, from coming out as Transgender, from facing their parents again in life, and from living a secluded life away from friends and family. Even if most of the parents of transgender people have thrashed them badly before discarding them, still while collecting data from them, the emotion of fear from being arrested was missing. Preferably, eight out of ten fathers proudly admitted that they severely battered their transgender child for taking birth as a transgender person in their home. three out of ten mothers exhibited fear in their face by lowering brows and stretching lips. These three respondents were frightened by their husband and expressed their feelings in their absence.

\footnotetext{
${ }^{2}$ When transgender people tell others about their gender identities, it's referred to as "coming out."
} 


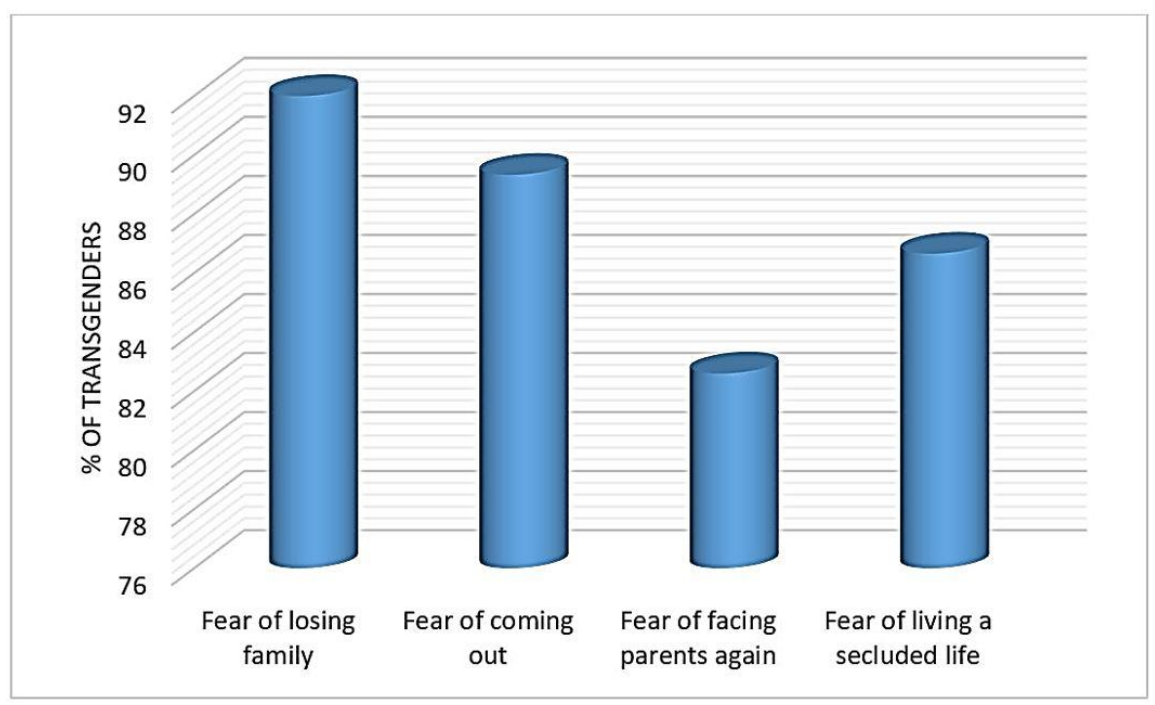

Fig1. Measurement of 'Fear' in Transgenders respondents

\section{Measuring the emotion 'Anger' in Transgender respondents and their Parents through}

\section{FACS}

Anger is a primary natural human emotion-induced by feelings of annoyance, displeasure, or antagonism. Anger is of two types, i.e., passive and aggressive anger. Passive anger deals with holding back anger inside without expressing it, whereas aggressive anger is expressed outwardly. In the case of transgender people, the resilience among them is high in comparison to others, which may be because of end to end prejudices faced by them from the very beginning of their coming out. However, it shows passive anger in them, but at the same time, most of the nontransgenders parents and peers exhibit aggression towards them because of the hatred towards their unique identity. It was observed that public criticism and harsh parenting mostly brought anger in transgender people. Most of the transgender people get raged when they are repeatedly mocked and criticized for their identity in public places by their peers or by any unknown individuals. Seventy-two transgender respondents expressed that criticizing them in public spaces provokes them to act violently. While expressing their views, their brows were lowered, upper lid rose and was tightened, and lips were tightened too, which illustrated their anger. Fifty-eight transgender people also expressed their anger on parents for rejecting them. Figure 5 shows that 72 transgender people were infuriated when criticized publicly and 58 enraged because of harsh parenting.

Most of the parents of transgender people expressed their anger on their transgender children by physically and verbally abusing them. Every transgender father from the sample gave the same expression of lowering brows, rising and tightening upper lids and tapering lips, which illustrate their anger for being destined to be a father to a transgender child. Seventeen out of twenty transgender parents expressed their anger while narrating their bitter past with their transgender child. 


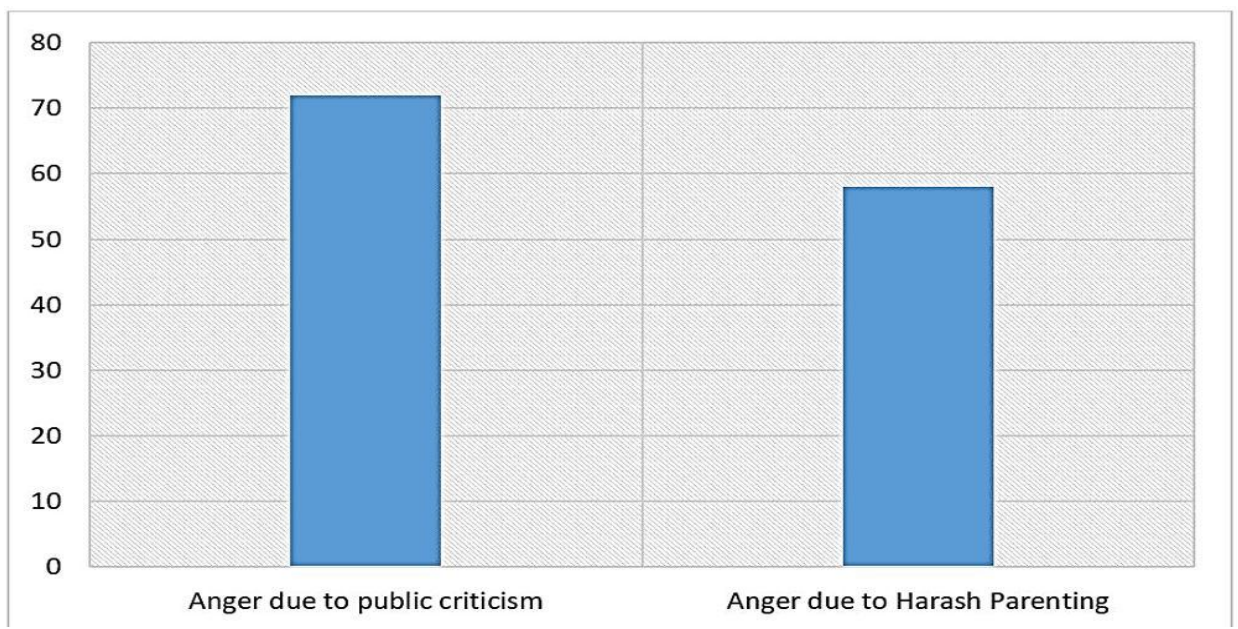

Fig.5: Anger in Transgender respondents due to public criticism or harsh parenting

Measuring the emotion 'Disgust' in Transgender respondents and their Parents through FACS

Disgust is an emotion of intense displeasure or dislikes for something offensive. From the narrations recorded from transgender people, it was evident that most of them are disgusted by the sense of unpleasant touch and from pretending as a man that they are not. Fifty-two transgender people were disgusted with the unpleasant touch during their childhood, and while begging and entertaining in railway stations, bus stops, and signal points. The respondents were exhibiting the facial expressions that imply being disgust with a wrinkling nose, depressing lip corner, and sometimes by depressing lower lip to an intensity rate of 'c'. However, political conservatism, religious fundamentalism, negative attitude, and moral foundation disapprove of the cisgender to accept Transgender. However, ten fathers and seven mothers were disgusted by being a parent to their transgender child, who was evident enough from their facial expressions after listening to the name of their transgender child. The disgusting stimulus in transgender parents implied their transphobia or anti-transgender feeling, which has adversely affected their transgender child.

\section{Measuring the emotion 'Contempt' in Transgender respondents and their}

\section{Parents through FACS}

Contempt refers to resentment towards an individual or a group or towards an ideology. It is a visceral emotion that is similar to disgust but is more about social distinctions. In the case of transgender people, they are Contempt when they are verbally abused and criticized in general. Forty-eight respondents expressed their Contempt over verbal and physical abuse by their parents, relatives, police, and sometimes public. The respondents moved their action units such as Lip Corner Puller and Dimpler, which shows their Contempt towards the gender abusive terms. This makes them feel inferior or like they deserve these abuses, which bring Contempt in them. However, no expression for Contempt was observed while collecting data from transgender parents. 


\section{Findings}

13.1. Negative Emotions of the Parents of Transgender respondents after Detachment

According to Friesen's and Ekman's visual guide book, for negative emotions, action units under sadness and disgust were taken into consideration. Transgender parents were found sad and disappointed for either being destined to have a transgender child (20/20) or an inability to convince other members of the family not to discard them $(3 / 20)$. All these three respondents expressed their emotions by raising inner brows, lowering brows, and depressing lip corner to intensity of rate 'c', which proved that they were sad. When asked about the feelings of being a parent to a transgender child, they expressed their grief with raising inner brows, lowering brows, and depressing lip corner to an intensity rate of ' $b$ ', which implied sadness in them. 17/20 respondents expressed their disgust being a parent to a transgender child by wrinkling the nose, depressing lip corner, and sometimes by depressing lower lip to an intensity rate of ' $c$ '.

13.2. Guilt over discarding Transgender child due to societal pressure

3 out of 10 mothers of Transgender expressed their utter sadness for not taking a stand for their transgender child. Further, they were in the guilt of failing as a mother and were highly concerned about their transgender child. Thus, most transgender mothers were surrounded by guilt and disappointment of unable to stop other family members from throwing their transgender child out. On the other hand, from the sample collected, all the fathers were sad for being a parent to a transgender child and blamed the destiny for it. They were disgust of being recognized as a father to a transgender child and exhibited their resentment on their transgender child by offending and thrashing them. However, all these three respondents expressed their emotions by raising inner brows, lowering brows, and depressing lip corner to intensity of rate 'c', which proved that they were sad.

13.3 Positive and negative Emotions in Transgender respondents after renouncing home

After coming out as a transgender person in front of parents and society, most of the transgender people were mercilessly shunned. They faced several challenges after being thrown away from their home. On the one hand, most of the transgender people took long to discover their gender identity. On the other hand, few after discovering it preferred pretending as the same person corresponding with the assigned sex at birth. However, the transgender people who chose to come out were offended by their parents and humiliated in their social circle. Some transgender people were discarded by their parents, and some preferred moving out of their own will either of being tired of pretending or due to the fear of earning a bad name to the family. Few of them felt relieved and happy to start a new life with their true identity, whereas most of them blamed their identity for their rough struggle and seclusion from parents and peers. However, from the sample collected, it found that transgender people with negative emotions outnumbered transgender people with positive emotions. As it can be seen in Table 2, under the emotion of happiness; $10.6 \%$ of transgender people are happy being born as a transgender person, $20 \%$ are happily leading a life as a transgender person, 30\% are happy staying away from home $86.66 \%$ are happy staying with their transgender friends. Whereas under the emotion of sadness, $89.33 \%$ of transgender people are unhappy being born as a transgender person, 80\% blame their identity for their rough journey, $69.33 \%$ are dissatisfied staying away from home, and $13.33 \%$ are disappointed staying with their transgender friends. Further, taking the emotion of disgust into account,52 
transgender people were disgusted with the unpleasant touch, and 19 were disgusted from pretending as a man which they were not in reality.

\section{Conclusion}

Human communicates $93 \%$ of emotions through their eyes and faces. One expresses one's emotional clap-trap only through one's face and eyes. Transgender's anxiety is well-identified through their narrative and facial expressions. They often experience social isolation because of their unique sex identity and, at the same time, make their way to new social existence. Transgender usually receive a direct rejection from their parents, which puts them at the social crossroads. The instability of body-mind and soul is seen in both parents and children together. Primarily because of this reason, one finds parents of transgender people to be sad because of their lack of strong social standing. However, one also finds alternate emotions of freedom from society and its fixed norms by boycotting their loved ones.

\section{Acknowledgement}

The author expresses sincere gratitude towards Dr. Seema Kumari Ladsaria, Assistant Professor, Kalinga Institute of IndustrialTechnology for her extraordinary cooperation and guidance throughout the research work.

\section{References}

Ekman P, Friesen WV, Hager JC (2002). Facial Action Coding System: The Manual on CD ROM, Salt Lake City: A Human Face.

Ellis, K. M., \& Eriksen, K. (2002). Transsexual and Transgenderist Experiences and Treatment Options. The Family Journal, 10(3), 289-299. https://doi.org/10.1177/10680702010003005

Factor, R. J., \& Rothblum, E. D. (2007). A Study of Transgender Adults and Their Non-Transgender Siblings on Demographic Characteristics, Social Support, and Experiences of Violence. Journal of LGBT Health Research, 3(3), 11-30. https://doi.org/10.1080/15574090802092879

Grossman, A. H., \& D’Augelli, A. R. (2006). Transgender Youth: Invisible and Vulnerable. Journal of Homosexuality, 51(1), 111-128. https://doi.org/10.1300/Jo82v51no1_o6

https://www.journalcra.com/article/status-transgender-population-odisha

Klein, R. (1999). Group Work Practice with Transgendered Male to Female Sex Workers. Journal of Gay \& Lesbian Social Services, 10(3-4), 95-109. https://doi.org/10.1300/Jo41v10no3_07

Lev, A. I. (2004). Transgender emergence: Therapeutic guidelines for working with gender-variant people and their families, New York, NY: Hayworth Press.

Lombardi, E. (2001). Enhancing transgender health care. American Journal of Public Health, 91(6), 869-872. https://doi.org/10.2105/AJPH.91.6.869

Mallon, G. P. (1999). Knowledge for Practice with Transgendered Persons. Journal of Gay \& Lesbian Social Services, 10(3-4), 1-18. https://doi.org/10.1300/Jo41v10no3_01

Pattnaik, I., \& Mohanty, Dr. A. (2014). Social Exclusion: A Challenge For The Status Of Third Gender People Of Odisha, IJSR - International Journal of Scientific Research(IJSR), IJSR | World Wide Journals.https://www.worldwidejournals.com/international-journal-of-scientific-research- 
(IJSR)/article/social-exclusion-a-challenge-for-the-status-of-third-gender-people-ofodisha/NDQzMw==/?is=1

Radloff, L. S. (1977). The CES-D Scale: A Self-Report Depression Scale for Research in the General Population. Applied Psychological Measurement, 1(3), 385-401.

https://doi.org/10.1177/014662167700100306

Ryan, null, \& Futterman, null. (1997). Lesbian and Gay Youth: Care and Counseling. Adolescent Medicine (Philadelphia, Pa.), 8(2), 207-374.

Singh, Dr. J. (2018). The status of transgender population in Odisha. International Journal of Current Research, 10(06).

Vanderburgh, R. (2007). Transition and beyond: Observations on gender identity. Portland, OR: Q Press.

Wren, B. (2002). 'I Can Accept My Child is Transsexual but if I Ever See Him in a Dress I'll Hit Him':

Dilemmas in Parenting a Transgendered Adolescent. Clinical Child Psychology and Psychiatry, 7(3), 377-397. https://doi.org/10.1177/1359104502007003006

Sugyanta Priyadarshini, is Research Scholar in Kalinga Institute of Industrial Technology. She graduated under Utkal University and was the topper of her batch in 2014. She was the gold medalist in her master's degree from Berhampur University. Her areas of interests are gender economics and health economics. She is currently pursuing her PhD and is interested in Gender Economics. She has published more that six articles, one book chapter and presented more than twelve conference publications. 